Article

\title{
Association between Dietary Patterns and Atopic Dermatitis in Relation to GSTM1 and GSTT1 Polymorphisms in Young Children
}

\author{
Jayong Chung ${ }^{1}$, Sung-Ok Kwon ${ }^{1}$, Hyogin Ahn ${ }^{1}$, Hyojung Hwang ${ }^{1}$, Soo-Jong Hong ${ }^{2}$ and \\ Se-Young $\mathrm{Oh}^{1, *}$
}

Received: 11 August 2015 ; Accepted: 2 November 2015 ; Published: 13 November 2015

1 Department of Food \& Nutrition, Research Center for Human Ecology, College of Human Ecology, Kyung Hee University, 26, Kyungheedae-ro, Hoegi-dong, Dongdaemun-gu, Seoul 02447, Korea; jchung@khu.ac.kr (J.C.); kamelon@hanmail.net (S.-O.K.); ddottori@naver.com (H.A.); fullmoon0118@naver.com (H.H.)

2 Department of Pediatrics, Childhood Asthma Atopy Center, Research Center for Standardization of Allergic Diseases, University of Ulsan College of Medicine 13, Gangdong-daero, Pungnap-dong, Songpa-gu, Seoul 05535, Korea; sjhong@amc.seoul.kr

* Correspondence: seyoung@khu.ac.kr; Tel.: +82-2961-0649; Fax: +82-2959-0649

\begin{abstract}
Previous research suggests the association of glutathione S-transferase (GST) gene polymorphisms or diet, but no interactions between these factors in atopic dermatitis (AD). We conducted a community-based case-control study including $194 \mathrm{AD}$ and 244 matched non-AD preschoolers. Glutathione S-transferase M1 (GSTM1) and T1 (GSTT1) present/null genotypes were evaluated uisng a multiplex PCR method. We measured dietary intakes by a validated food frequency questionnaire and constructed three dietary patterns such as "traditional healthy", "animal foods", and "sweets" diets. In stratified analyses by GST genotypes, the "traditional healthy" diet and reduced AD showed association only in the GSTM1-present group (odd ratio (OR) $0.31,95 \%$ confidence interval (CI) $0.13-0.75$ ). A similar pattern of the association existed in the combined GSTM1/T1 genotype that indicated the inverse association between the "traditional healthy" diet and AD in the double GSTM1/T1-present genotype group (OR 0.24, 95\% CI 0.06-0.93). Results from the multiplicative test analyses showed that the "traditional healthy" diet on reduced AD was significant or borderline significant in the GSTM1-present group (OR 0.71, 95\% CI 0.54-0.92 vs. GSTM1-null group) or the GSTM1/T1 double present group (OR 0.63, 95\% CI 0.39-1.03 vs. GSTM1/T1 double null group). These findings demonstrate that the present type of GSTM1 may increase susceptibility to the potential effect of the "traditional healthy" diet on AD.
\end{abstract}

Keywords: dietary patterns; GST gene; polymorphisms; atopic dermatitis; young children

\section{Introduction}

Atopic dermatitis (AD) is a chronic and relapsing inflammatory skin disease. It is one of the most common allergic diseases in children, affecting up to $25 \%$ worldwide [1]. Comparable or even greater prevalence of $\mathrm{AD}(25 \%-34 \%)$ has been reported in a large scale study of Korean children [2]. The majority of AD starts in early childhood, and $70 \%$ of children with AD show clinical symptoms before the age of five years [3,4]. As $\mathrm{AD}$ is a major health concern that severely compromises quality of life in children, understanding the factors associated with the development of $\mathrm{AD}$ and its prevention are critical.

Multiple genetic and environmental factors are thought to contribute to the risk and development of $\mathrm{AD}$. AD is usually associated with a family history of atopic disorders, such 
as asthma, rhinitis, and AD itself, and twin studies have shown that the genetic contribution is substantial [5]. However, a steady increase in the prevalence of $\mathrm{AD}$ over recent decades indicates that environmental factors also play important roles in AD pathogenesis. Although the molecular mechanisms underlying $\mathrm{AD}$ are not fully understood, impaired homeostasis of oxygen/nitrogen radicals as well as increased oxidative stress have been suggested to be involved in the pathophysiology of childhood $\mathrm{AD}[6,7]$. In skin inflammation associated with AD, reactive oxygen species are released during the activation and infiltration of lymphocytes, monocytes, and eosinophils [8,9].

Diet has been suggested as a predictor of health such as allergic diseases and mental health in childhood [10-16], although the actual association is not clear. Previously, we have demonstrated that a higher intake of dietary antioxidant vitamins, including $\beta$-carotene and vitamin $E$, is associated with a reduced risk of AD among preschool-age children in Korea and suggested a possible role of oxidative stress in this association [10]. Dietary pattern providing an overall view of intake draws attention because it could minimize chance inter-correlations among many nutrients in the diet. "Processed" or "Western" diets, high in fat and sugar content, or "healthy" or "prudent" diets, containing micronutrient-rich foods, have been reported regarding child mental health, although the associations are not clear [13-16].

Genetic variations in glutathione S-transferase (GST) that alter enzymatic activity can have a significant impact on susceptibility to diseases whose pathogenesis involves oxidative stress, as is the case in many inflammatory diseases such as atopic dematitis (AD) [17-20]. Several genetic polymorphisms have been identified in GST isoforms. A limited number of studies [21,22], including one of our own [23], have examined the association of GST gene polymorphisms with AD, yet the findings are inconsistent.

Considering that both genetic and environmental factors are important contributors to AD development, we hypothesize that interactions between genetic determinants of antioxidant capacity and diet may play a role in AD. Therefore, in the present study, we examined the association between dietary patterns and $\mathrm{AD}$ in relation to glutathione S-transferase M1 (GSTM1) and T1 (GSTT1)-present/null polymorphisms.

\section{Methods}

\subsection{Participants and Study Design}

As shown in Figure 1, at the beginning, our participants were from a population based and matched case-control study including 781 subjects who were selected by screening eligibility from 2638 preschoolers residing in middle-income areas in large cities in Korea such as Seoul and Incheon between May and July $2006[10,23]$. We assessed the child's AD by the Korean version of ISAAC (The International Study of Asthma and Allergies in Childhood) [10,23]. Case subjects were children who had experienced AD symptoms in the form of AD diagnosis or treatment $(n=351)$, and controls were matched by the same preschools $(n=430)$, considering both age and gender. Of those 781 participants, we excluded 343 children who had no dietary intake variables ( $n=179 ; 82 \mathrm{AD}, 97$ non-AD), energy intake less than $500 \mathrm{kcal}$ or greater than $4,500 \mathrm{kcal}(n=15 ; 7 \mathrm{AD}, 8$ non-AD), modified diet by AD $(n=36 ; 26 \mathrm{AD}, 10$ non-AD) or other diseases $(n=8 ; 7 \mathrm{AD}, 1$ non-AD), or no genetic information ( $n=105 ; 35 \mathrm{AD}, 70$ non-AD). A total of 438 (194 AD, 244 non-AD) children were included in our data analyses (Figure 1). Due to the exclusion of a large number of children, we did comparison analysis including the child's age (5.3 vs. 5.2 years), BMI ( 15.4 vs. 15.5$)$ and gender ( $48.3 \%$ vs. $50.3 \%$ for girls), as well as household monthly income (38.4\% vs. $33.8 \%$ for greater than 4 million Korean Won, close to 4000 US \$). There was no significant group difference in these variables (Supplementary Table S1).

Data on dietary intake, $\mathrm{AD}$, and other related information were collected by questionnaires. Blood samples were taken for the analyses of genetic information and total IgE concentration between September 2006 and January 2007. 


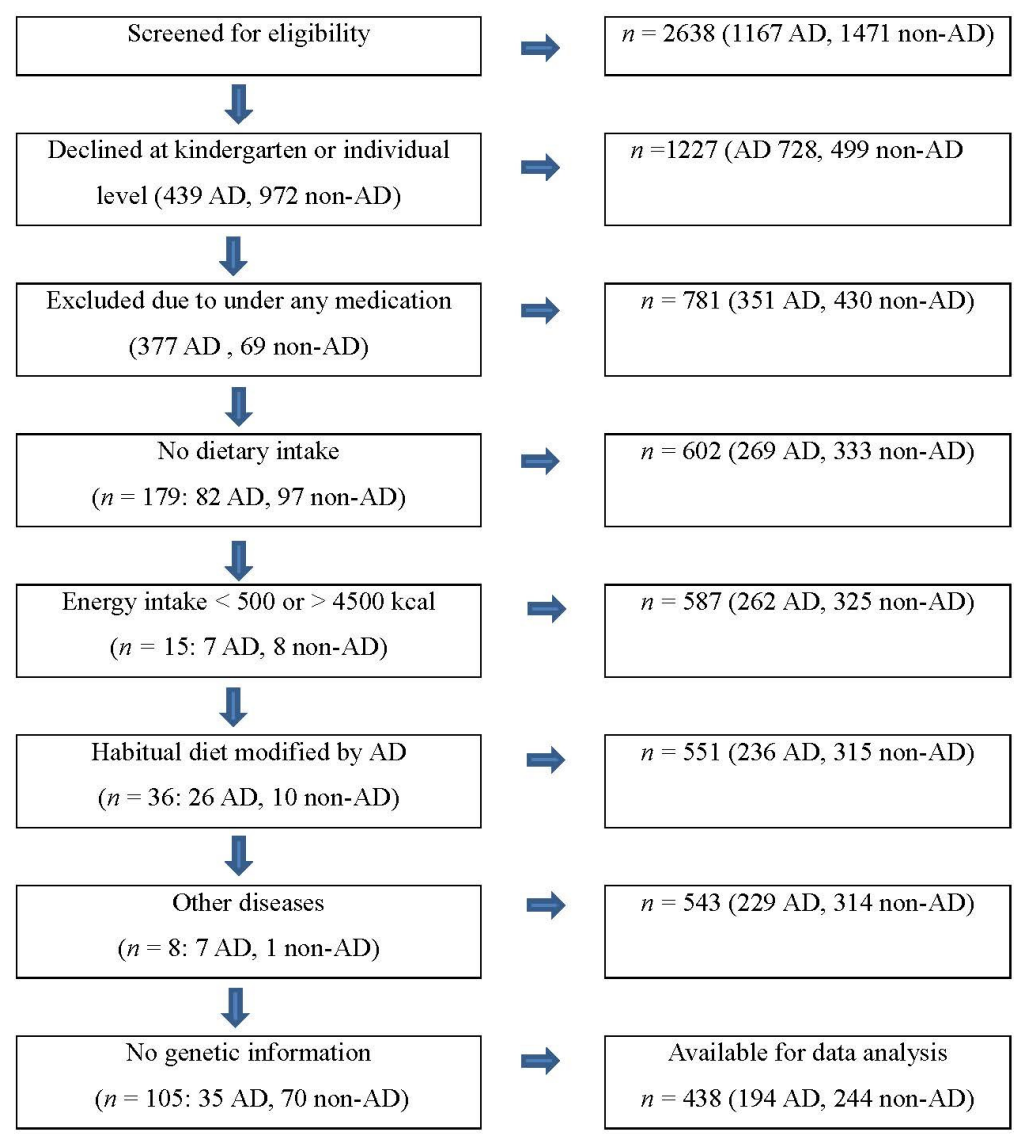

Figure 1. Sample selection process. Atopic Dermatitis (AD).

\subsection{Dietary Assessment}

We assessed dietary intake through a validated semi-quantitative food frequency questionnaire (FFQ) used in other studies [10,24]. Reproducibility $(r=0.5-0.8)$ and validity $(r=0.3-0.6)$ of this instrument were both acceptable $[10,24]$. The FFQ contains 86 food items with nine non-overlapping frequency response categories as well as three portion size options (low 0.5, medium 1, high 1.5). Using CAN PRO II (Computer-Aided Nutritional Analysis Program II), developed by the Korean Nutrition Society, the amount of each food item in the FFQ was converted into grams, after which daily intakes of nutrients were calculated.

To develop dietary patterns for this study group, we used 84 food items, excluding two rarely eaten foods (organ meat and fermented salty fish). From the 84 food items, our analysis consisted of $33 \mathrm{food} /$ food groups based on nutrient profiles of each food item (Table 1).

Table 1. Thirty-three food groups used in statistical analyses with factor analysis.

\begin{tabular}{cl}
\hline Food/Food Group & \multicolumn{1}{c}{ Food } \\
\hline Beans & Soybean curd (tofu)/curd residue, soybean (boiled with soy sauce), soymilk \\
Beef & Sliced beef with sauces (Galbi, Bulgogi), beef (loin, tender loin), beef soup/beef \\
broiled down in soy \\
Bread & White and dark breads \\
Cereals & Breakfast cereals \\
Cheese & Cheese \\
Chicken & Chicken (fried), chicken (boiled, braised) \\
Chocolate & Chocolate \\
Eggs & Eggs \\
\hline
\end{tabular}


Table 1. Cont.

\begin{tabular}{|c|c|}
\hline Fast food & Hamburger, pizza, French fries \\
\hline Eggs & Eggs \\
\hline Fast food & Hamburger, pizza, French fries \\
\hline Fats & Butter/margarine, mayonnaise \\
\hline Fresh fish & $\begin{array}{l}\text { White fish (pan fried, fried), white fish (grilled, broiled down in soy) blue fish } \\
\text { (pan fried, fried), blue fish (grilled, broiled down in soy), squid/octopus, } \\
\text { shrimps, clams/oysters }\end{array}$ \\
\hline Fruit juice & Orange juice, tomato juice, other fruit juices \\
\hline Fruits & $\begin{array}{l}\text { Strawberries, apple, pear, mandarin/orange, tomato, banana, } \\
\text { melon/muskmelon, watermelon, peaches/plum, grapes }\end{array}$ \\
\hline Ice cream & Ice cream \\
\hline Kimchi & $\begin{array}{l}\text { Korean cabbage kimchi/seasoned cubed radish roots/young radish kimchi, } \\
\text { other kinds of kimchi }\end{array}$ \\
\hline Milk & Whole milk, flavored milk, low fat milk \\
\hline Mulchi & Anchovy (stir-fried) \\
\hline Noodles \& Dumplings & Korean style noodles, spaghetti/bean sauce noodles, dumplings \\
\hline Nuts & Nuts \\
\hline Pork & Pork (loin, tender loin, shoulder), pork (belly) \\
\hline Potatoes & Potatoes, sweet potatoes (not fried) \\
\hline Processed fish & Canned tuna, fish paste \\
\hline Processed meat & Ham/sausage \\
\hline Ramyeon & Ramyeon \\
\hline Rice & White rice, other grains \\
\hline Rice cake & Rice cakes \\
\hline Seaweeds & Dried laver, sea mustard \\
\hline Snacks & Chips, crackers \\
\hline Sweet bread & Sweet bread \\
\hline Sweet drinks & Cocoa, soft drinks, sport drinks, traditional sweet drinks \\
\hline Sweets & Candies, jam \\
\hline Vegetables & $\begin{array}{l}\text { Lettuce/cabbage (raw), lettuce/cabbage (cooked), radish, bean } \\
\text { sprout/mungbean sprout, cucumber, spinach, perilla leaves, unripe hot pepper, } \\
\text { onion, carrots, squash, mushrooms, roots of balloon flower/fernbrake }\end{array}$ \\
\hline Yogurt & Yogurt, yogurt drinks \\
\hline
\end{tabular}

\subsection{Genotyping}

Genotypes for GSTM1 and GSTT1 present/null polymorphisms were assessed as described by Chung et al. [23]. Genomic DNA was extracted from buffy coats using an AxyPrep ${ }^{\mathrm{TM}}$ Blood Genomic DNA miniprep kit (Axygen Biosciences, Union City, CA, USA), after which multiplex PCR analyses were performed. Briefly, GSTM1, GSTT1, and $\beta$-globin genes were simultaneously amplified by PCR along with mixed primers for each gene. PCR conditions were as follows: initial denaturation at $94{ }^{\circ} \mathrm{C}$ for $3 \mathrm{~min}$, followed by 27 cycles of $94^{\circ} \mathrm{C}$ for $30 \mathrm{~s}, 62^{\circ} \mathrm{C}$ for $30 \mathrm{~s}$, and $72^{\circ} \mathrm{C}$ for $45 \mathrm{~s}$, and a final extension step of $10 \mathrm{~min}$ at $72{ }^{\circ} \mathrm{C}$. After amplification, PCR products were analyzed on a $2 \%$ agarose gel and stained with ethidium bromide. The presence or absence of GSTT1 (480 bp) and GSTM1 (215 bp) genes was determined in the presence of the control $\beta$-globin gene ( $268 \mathrm{bp})$.

\subsection{Other Factors}

Using a questionnaire, we measured household monthly income, parental education level, and child's age as continuous variables, and parental allergic history including AD, asthma, or rhinitis, and child's gender, nutrient supplement intake, and current exposure to smoking at home as categorical variables. Height and weight of children were measured by following recommended standard procedures [25]. Body mass index (BMI) was calculated by using height and weight measures. Serum total IgE concentrations were determined by EIA (AutoCAP system, Pharmacia, Uppsala, Sweden). 


\subsection{Statistical Analysis}

Based on the 33 food/food groups (Table 1) with daily intake frequency values per $1000 \mathrm{kcal}$, we performed factor analysis to develop dietary patterns with varimax rotation [26]. Three dietary patterns were selected in accordance with the eigenvalue ( $>1.5)$, scree plots, and interpretability of factors. We calculated factor loadings for each food/food group across the three dietary factors, and a factor score for each subject obtained for the $33 \mathrm{food} /$ food groups, in which intakes of food groups were weighted by their factor loadings and summed.

We named dietary patterns based on food/food groups with the most positive factor loadings. The "traditional healthy" pattern was identified by considering relatively higher intakes of vegetables, fruits, seaweeds, beans, anchovies, potatoes, fresh fish, kimchi, and cheese, as well as lower intake of ramyeon. The "animal foods" pattern was characterized by higher intakes of beef, pork, poultry, fish, and fast foods, in addition to noodles and rice cake. The "sweets" included higher intakes of fruit juice, sweet drinks, chocolate, snacks, and ice cream, but lower intake of rice (Table 2).

Table 2. Factor-loading matrix for defining dietary patterns by the factor analysis using 33 food or food group variables $(n=438)$.

\begin{tabular}{|c|c|c|c|}
\hline Food/Food Groups & Traditional Healthy & Animal Foods & Sweets \\
\hline Vegetables & 0.62 & 0.13 & -0.13 \\
\hline Fruit & 0.58 & -0.01 & 0.18 \\
\hline Seaweeds & 0.48 & 0.06 & -0.02 \\
\hline Beans & 0.44 & 0.01 & 0.10 \\
\hline Mulchi & 0.46 & -0.03 & -0.06 \\
\hline Potatoes & 0.46 & 0.21 & -0.04 \\
\hline Kimchi & 0.38 & -0.08 & -0.22 \\
\hline Fresh fish & 0.37 & 0.21 & -0.10 \\
\hline Ramyeon & -0.35 & 0.29 & -0.17 \\
\hline Noodles and dumplings & -0.21 & 0.52 & 0.03 \\
\hline Bread & 0.04 & 0.49 & 0.12 \\
\hline Rice cake & 0.15 & 0.48 & -0.04 \\
\hline Chicken & -0.07 & 0.47 & -0.02 \\
\hline Fast food & -0.19 & 0.43 & 0.19 \\
\hline Sweet bread & -0.03 & 0.40 & 0.06 \\
\hline Beef & 0.15 & 0.37 & 0.04 \\
\hline Sweets & -0.01 & 0.36 & 0.35 \\
\hline Fats & 0.11 & 0.33 & -0.01 \\
\hline Pork & 0.05 & 0.30 & 0.05 \\
\hline Processed meat & -0.21 & 0.28 & 0.09 \\
\hline Processed fish & 0.09 & 0.25 & 0.01 \\
\hline Milk & 0.01 & -0.34 & 0.19 \\
\hline Fruit juice & 0.24 & 0.01 & 0.50 \\
\hline Sweet drinks & -0.23 & 0.17 & 0.46 \\
\hline Chocolate & -0.14 & 0.14 & 0.46 \\
\hline Snacks & -0.28 & 0.14 & 0.41 \\
\hline Ice cream & 0.02 & 0.06 & 0.38 \\
\hline Cheese & 0.32 & -0.13 & 0.33 \\
\hline Rice & -0.23 & -0.01 & -0.60 \\
\hline Yogurt & 0.20 & -0.23 & 0.29 \\
\hline Eggs & 0.16 & 0.15 & -0.27 \\
\hline Nuts & 0.27 & -0.05 & 0.27 \\
\hline Cereals & -0.04 & 0.02 & 0.16 \\
\hline
\end{tabular}

Each dietary pattern was divided into high (Q4) and low (Q1-Q3) groups according to the quartiles of dietary pattern scores. In addition to initial crude models, multivariate logistic regression models were used to estimate the effects of dietary patterns and GST genotypes on AD. As potential residual confounders, parental allergic history, maternal education level, household income, and 
child's age, gender, BMI, total energy and nutrient supplement intakes, and secondary smoking exposure had been considered. Among these variables, household income, maternal education level, and child's secondary smoking exposure were excluded in the analytic model because these variables did not show any significant difference between $\mathrm{AD}$ and non-AD groups.

To investigate the association between dietary patterns and AD with respect to GST genotypes, stratified analyses were performed after dividing the subjects into two groups for the GSTM1 and GSTT1 (null and present), and three groups for the GSTM1/T1 (double null, either present, or double present). The stratified analysis by GST genotype was conducted adjusted for the confounders in the corresponding model. Multiplicative interactions were performed using the corresponding models that included the interaction term to examine the modifying effect of GST genotypes on the association between dietary patterns and AD. Results were reported as odds ratios (OR) and 95\% confident intervals (CI). Significance was set at $p<0.05$. Statistical analyses were conducted with SAS version 9.3 (SAS Institute Inc., Cary, NC, USA).

\subsection{Ethics Statement}

This study was conducted in accordance with the guidelines detailed in the Declaration of Helsinki, and all procedures involving human subjects were approved by the Institutional Review Board of the College of Human Ecology at Kyung Hee University [10,23]. Written informed consent was obtained from all parents of participating children.

\section{Results}

When we compared the high $(\mathrm{Q} 4)$ and low $(\mathrm{Q} 1-\mathrm{Q} 3)$ groups of dietary patterns, the "traditional healthy" diet was associated with higher intakes of protein, unsaturated fat, and micronutrients (Table 3). In particular, higher intakes of $\beta$-carotene and vitamin C (2.1 and 1.5-fold difference between the high and low groups, respectively) were substantial. The "animal foods" dietary pattern showed higher intakes of macronutrients except for plant protein and saturated fatty acids (SFA), but had no associations with micronutrients excluding vitamin E. The "sweets" diet was relevant to higher intakes of energy, plant fat, SFA, retinol, and vitamin C, as well as a lower intake of plant protein.

When we compared nutrient intakes by $\mathrm{AD}, \mathrm{AD}$ showed an association with lower intakes of vitamin $\mathrm{E}$, folate, and possibly $\beta$-carotene (Table 4). General characteristics were similar between $\mathrm{AD}$ and non-AD children except for child's total IgE concentration and allergic history of parents (Table 4). In the AD group, the majority of children ( $80.4 \%$ ) showed experience of physician's diagnosis of AD, followed by AD symptoms (45.8\%-49.5\%) and AD treatment (22.6\%).

The proportions of children with the null genotype in GSTM1 and GSTT1 were close to $60 \%$ and 50\%, respectively (Table 5). When the GSTM1 and GSTT1 genotypes were combined, about 30\% of children carried the null genotype for both genes. There were no associations of AD with GST genotypes and dietary patterns in univariate analyses.

In stratified analyses by GST genotypes (Table 6), the "traditional healthy" diet and reduced AD showed association only in the GSTM1-present group (OR 0.31, 95\% CI 0.13-0.75). A similar pattern of the association existed in the combined GSTM1/T1 genotype, which indicated an inverse association between the "traditional healthy" diet and AD in the double GSTM1/T1-present genotype group (OR 0.24, 95\% CI 0.06-0.93). There was a stronger association between the "traditional healthy" diet and $\mathrm{AD}(7 \%)$ in the GSTM1/T1 double present group (OR 0.24) than the case of GSTM1-present (OR 0.31) group. Results from the multiplicative test analyses showed that the "traditional healthy" diet on reduced AD was significant or borderline significant in the GSTM1-present group (OR $0.71,95 \%$ CI $0.54-0.92$ vs. GSTM1-null group) or the GSTM1/T1 double present group (OR 0.63, 95\% CI 0.39-1.03 vs. GSTM1/T1 double null group). These associations did not exist in the "animal foods" and "sweets" dietary patterns. 
Table 3. Associations of daily nutrient intakes with dietary patterns between the low (Q1-Q3, $n=329)$ and high (Q4, $n=109)$ groups *

\begin{tabular}{|c|c|c|c|c|c|c|c|c|c|c|c|c|c|c|c|}
\hline \multirow{3}{*}{ Nutrient } & \multicolumn{5}{|c|}{ Traditional Healthy } & \multicolumn{5}{|c|}{ Animal Foods } & \multicolumn{5}{|c|}{ Sweets } \\
\hline & \multicolumn{2}{|c|}{ Low (Q1-Q3) } & \multicolumn{2}{|c|}{ High (Q4) } & \multirow{2}{*}{$p$} & \multicolumn{2}{|c|}{ Low (Q1-Q3) } & \multicolumn{2}{|c|}{ High (Q4) } & \multirow{2}{*}{$p$} & \multicolumn{2}{|c|}{ Low (Q1-Q3) } & \multicolumn{2}{|c|}{ High (Q4) } & \multirow{2}{*}{$p$} \\
\hline & Mean & SE & Mean & SE & & Mean & SE & Mean & SE & & Mean & SE & Mean & SE & \\
\hline Energy $(\mathrm{kJ})$ & 1556.3 & 37.1 & 1511.9 & 64.5 & 0.551 & 1583.0 & 37.0 & 1431.4 & 64.2 & 0.041 & 1497.5 & 36.8 & 1689.3 & 64.0 & 0.010 \\
\hline Animal protein $(\mathrm{g})$ & 32.0 & 0.6 & 39.3 & 1.1 & $<.0 .001$ & 32.8 & 0.6 & 36.8 & 1.1 & 0.003 & 33.9 & 0.7 & 33.4 & 1.1 & 0.706 \\
\hline Plant protein $(\mathrm{g})$ & 22.6 & 0.3 & 23.8 & 0.5 & 0.048 & 23.1 & 0.3 & 22.5 & 0.5 & 0.363 & 23.7 & 0.3 & 20.5 & 0.5 & $<0.001$ \\
\hline Animal fat (g) & 28.0 & 0.6 & 32.6 & 1.1 & $<0.001$ & 28.4 & 0.6 & 31.5 & 1.1 & 0.011 & 28.7 & 0.6 & 30.5 & 1.1 & 0.140 \\
\hline Plant fat $(\mathrm{g})$ & 18.5 & 0.4 & 20.8 & 0.7 & 0.004 & 18.0 & 0.4 & 22.4 & 0.7 & $<0.001$ & 17.9 & 0.4 & 22.8 & 0.7 & $<0.001$ \\
\hline Vitamin A $(\mu \mathrm{g}, \mathrm{RE})$ & 413.6 & 10.3 & 652.4 & 17.8 & $<0.001$ & 481.1 & 11.7 & 448.7 & 20.4 & 0.170 & 459.9 & 11.7 & 512.8 & 20.4 & 0.025 \\
\hline Retinol $(\mu \mathrm{g})$ & 229.5 & 5.7 & 258.5 & 9.9 & 0.012 & 240.8 & 5.7 & 224.4 & 10.0 & 0.157 & 216.3 & 5.4 & 298.2 & 9.5 & $<0.001$ \\
\hline$\beta$-carotene $(\mu \mathrm{g})$ & 1247.3 & 55.0 & 2561.9 & 95.6 & $<0.001$ & 1598.4 & 63.4 & 1502.3 & 110.4 & 0.452 & 1560.3 & 63.5 & 1617.3 & 110.7 & 0.656 \\
\hline Vitamin C (mg) & 65.3 & 2.3 & 97.3 & 4.0 & $<0.001$ & 73.8 & 2.4 & 71.6 & 4.2 & 0.659 & 65.6 & 2.3 & 96.4 & 4.0 & $<0.001$ \\
\hline Folate $(\mu \mathrm{g})$ & 172.1 & 2.8 & 231.4 & 4.9 & $<0.001$ & 188.7 & 3.1 & 181.3 & 5.5 & 0.242 & 186.6 & 3.2 & 187.8 & 5.5 & 0.855 \\
\hline Vitamin E (mg, $\alpha$-TE) & 8.5 & 0.2 & 12.3 & 0.4 & $<0.001$ & 8.7 & 0.2 & 11.6 & 0.4 & $<0.001$ & 9.5 & 0.2 & 9.2 & 0.4 & 0.513 \\
\hline Saturated fatty acids (g) & 12.1 & 0.3 & 13.1 & 0.6 & 0.131 & 12.5 & 0.3 & 11.9 & 0.6 & 0.326 & 11.9 & 0.3 & 13.8 & 0.6 & 0.004 \\
\hline Monounsaturated fatty acids (g) & 8.0 & 0.2 & 9.7 & 0.4 & $<0.001$ & 8.1 & 0.2 & 9.4 & 0.4 & 0.003 & 8.3 & 0.2 & 8.8 & 0.4 & 0.224 \\
\hline Polyunsaturated fatty acids (g) & 3.9 & 0.1 & 5.5 & 0.2 & $<0.001$ & 4.0 & 0.1 & 5.2 & 0.2 & $<0.001$ & 4.3 & 0.1 & 4.2 & 0.2 & 0.749 \\
\hline
\end{tabular}

Abbreviations: $\mathrm{SE}$ = standard error, $\mathrm{RE}=$ retinol equivalents, $\mathrm{TE}$ = tochopherol equivalents; * Adjusted for energy intake except for the energy variable. 
Table 4. Associations of nutrient intakes and general characteristics with atopic dermatitis (AD) in young children.

\begin{tabular}{|c|c|c|c|c|c|}
\hline & \multicolumn{2}{|c|}{$\operatorname{AD}(n=194)$} & \multicolumn{2}{|c|}{ Non-AD $(n=244)$} & \multirow{2}{*}{$p^{*}$} \\
\hline & Mean & SD & Mean & SD & \\
\hline Age (year) & 5.4 & 1.2 & 5.3 & 1.3 & 0.270 \\
\hline $\operatorname{BMI}\left(\mathrm{kg} / \mathrm{m}^{2}\right)$ & 18.3 & 3.5 & 17.9 & 3.4 & 0.260 \\
\hline Birth weight (kg) & 3.3 & 0.7 & 3.3 & 0.8 & 0.876 \\
\hline \multicolumn{6}{|l|}{ Daily nutrient intake } \\
\hline Energy $(\mathrm{kJ})$ & 6305.2 & 2622.3 & 6592.8 & 2957.5 & 0.289 \\
\hline Animal protein $(\mathrm{g})$ & 31.8 & 18.6 & 35.4 & 23.3 & 0.073 \\
\hline Plant protein $(\mathrm{g})$ & 22.4 & 9.4 & 23.3 & 10.2 & 0.324 \\
\hline Animal fat (g) & 27.5 & 16.8 & 30.5 & 21.0 & 0.095 \\
\hline Plant fat $(\mathrm{g})$ & 18.2 & 10.5 & 19.8 & 11.9 & 0.130 \\
\hline Vitamin A ( $\mu$ g RE) & 442.5 & 274.3 & 497.3 & 321.0 & 0.055 \\
\hline Retinol $(\mu \mathrm{g})$ & 231 & 158.8 & 241.2 & 161.8 & 0.509 \\
\hline$\beta$-carotene $(\mu \mathrm{g})$ & 1442.2 & 1244.3 & 1679.6 & 1397.8 & 0.065 \\
\hline Vitamin C (mg) & 69.3 & 57.1 & 76.4 & 61.8 & 0.217 \\
\hline Folate $(\mu \mathrm{g})$ & 173.8 & 88.0 & 197.3 & 106.5 & 0.012 \\
\hline Vitamin E (mg $\alpha$-TE) & 8.5 & 5.3 & 10.2 & 7.4 & 0.005 \\
\hline Saturated fatty acids (g) & 11.9 & 7.8 & 12.7 & 9.1 & 0.357 \\
\hline Monounsaturated fatty acids (g) & 7.8 & 4.6 & 8.8 & 6.8 & 0.072 \\
\hline Polyunsaturated fatty acids (g) & 3.9 & 2.4 & 4.6 & 3.5 & 0.009 \\
\hline \multirow[t]{2}{*}{ Total $\operatorname{IgE}(\mathrm{U} / \mathrm{mL})^{\dagger}$} & 325.8 & 617.2 & 187.7 & 307.9 & 0.006 \\
\hline & $n$ & $(\%)$ & $n$ & $(\%)$ & \\
\hline Gender (boys) & 103 & $(53.4)$ & 123 & $(50.4)$ & 0.539 \\
\hline \multicolumn{6}{|l|}{ AD status $\ddagger$} \\
\hline Symptoms $(n=192)$ & 88 & 45.8 & & & \\
\hline Itchy rash in the last year $(n=180)$ & 89 & 49.5 & & & \\
\hline Diagnosis by physician $(n=194)$ & 156 & 80.4 & & & \\
\hline Treatment $(n=190)$ & 43 & 22.6 & & & \\
\hline Current exposure to smoking at home & 31 & $(17.0)$ & 35 & $(15.4)$ & 0.645 \\
\hline Supplementary multivitamin use & 80 & $(46.0)$ & 110 & $(48.9)$ & 0.564 \\
\hline \multicolumn{6}{|l|}{ Household income $\left(10^{4} \text { Won } / \mathrm{mo}\right)^{\S}$} \\
\hline$<200$ & 28 & $(15.0)$ & 30 & $(12.7)$ & 0.733 \\
\hline 200-399 & 90 & $(48.1)$ & 113 & $(47.7)$ & \\
\hline$\geqslant 400$ & 69 & $(36.9)$ & 94 & $(39.7)$ & \\
\hline Maternal educational level ( $\geqslant 16$ year) & 86 & $(44.8)$ & 99 & $(40.7)$ & 0.396 \\
\hline \multicolumn{6}{|l|}{ Allergic history of mother } \\
\hline Asthma & 9 & $(4.6)$ & 13 & $(5.3)$ & 0.743 \\
\hline Rhinitis & 46 & $(23.7)$ & 57 & $(23.4)$ & 0.932 \\
\hline $\mathrm{AD}$ & 26 & $(13.4)$ & 14 & $(5.7)$ & 0.006 \\
\hline \multicolumn{6}{|l|}{ Allergic history of father } \\
\hline Asthma & 9 & $(4.6)$ & 6 & $(2.5)$ & 0.213 \\
\hline Rhinitis & 47 & $(24.2)$ & 35 & (14.3) & 0.008 \\
\hline $\mathrm{AD}$ & 22 & $(11.3)$ & 17 & $(7.0)$ & 0.110 \\
\hline
\end{tabular}

Abbreviations: $\mathrm{RE}=$ retinol equivalents, $\mathrm{TE}=$ tochopherol equivalents; $^{*}$ Unadjusted $;{ }^{\dagger} n=182$ for $\mathrm{AD}, n=232$ for Non-AD; ${ }^{\ddagger}$ Only for AD group; ${ }^{\S}$ Approximately $10^{4}$ Won $=10$ US dollars. 
Table 5. Associations of the glutathione S-transferase M1 (GSTM1) and T1 (GSTT1) genotypes and dietary patterns with atopic dermatitis (AD).

\begin{tabular}{|c|c|c|c|c|c|}
\hline & \multicolumn{2}{|c|}{ AD } & \multicolumn{2}{|c|}{ Non-AD } & \multirow{2}{*}{$p^{*}$} \\
\hline & $n$ & $\%$ & $n$ & $\%$ & \\
\hline \multicolumn{6}{|l|}{ Genotypes } \\
\hline GSTM1 & & & & & 0.466 \\
\hline Null & 118 & 60.8 & 140 & 57.4 & \\
\hline Present & 76 & 39.2 & 104 & 42.6 & \\
\hline GSTT1 & & & & & 0.686 \\
\hline Null & 98 & 50.5 & 128 & 52.5 & \\
\hline Present & 96 & 49.5 & 116 & 47.5 & \\
\hline GSTM1/GSTT1 & & & & & 0.638 \\
\hline Double null & 57 & 29.4 & 75 & 30.7 & \\
\hline Either null & 102 & 52.6 & 118 & 48.4 & \\
\hline Double present & 35 & 18.0 & 51 & 20.9 & \\
\hline Dietary patterns & & & & & \\
\hline Traditional healthy & & & & & 0.466 \\
\hline Low (Q1-Q3) & 149 & 45.3 & 180 & 54.7 & \\
\hline High (Q4) & 45 & 41.3 & 64 & 58.7 & \\
\hline Animal foods & & & & & 0.873 \\
\hline Low (Q1-Q3) & 145 & 44.1 & 184 & 55.9 & \\
\hline High (Q4) & 49 & 45.0 & 60 & 55.0 & \\
\hline Sweets & & & & & 0.776 \\
\hline Low (Q1-Q3) & 147 & 44.7 & 182 & 55.3 & \\
\hline High (Q4) & 47 & 43.1 & 62 & 56.9 & \\
\hline
\end{tabular}

Table 6. Association between dietary pattern and atopic dermatitis (AD) by of the glutathione S-transferase M1 (GSTM1) and /or T1 (GSTT1) genotypes $(n=438)$ *.

\begin{tabular}{|c|c|c|c|c|c|c|}
\hline & \multicolumn{6}{|c|}{ AD vs. Non AD } \\
\hline & aOR & $95 \% \mathrm{CI}$ & $p$ for Chi-Square & $\mathrm{aOR}$ & $95 \% \mathrm{CI}$ & $p$ for Interaction \\
\hline \multicolumn{7}{|l|}{ Tradition healthy } \\
\hline \multicolumn{7}{|l|}{ GSTM1 } \\
\hline Null & 1.24 & $(0.68,2.26)$ & 0.495 & 1 & & \\
\hline Present & 0.31 & $(0.13,0.75)$ & 0.009 & 0.71 & $(0.54,0.92)$ & 0.011 \\
\hline \multicolumn{7}{|l|}{ GSTT1 } \\
\hline Null & 0.67 & $(0.34,1.30)$ & 0.239 & 1 & & \\
\hline Present & 0.90 & $(0.45,1.81)$ & 0.788 & 1.08 & $(0.85,1.37)$ & 0.542 \\
\hline \multicolumn{7}{|l|}{ GSTM1/GSTT1 } \\
\hline Double null & 0.93 & $(0.41,2.13)$ & 0.881 & 1 & & \\
\hline Either null & 0.97 & $(0.49,1.90)$ & 0.931 & 1.27 & $(0.90 .1 .37)$ & 0.176 \\
\hline Double present & 0.24 & $(0.06,0.93)$ & 0.039 & 0.63 & $(0.39,1.03)$ & 0.065 \\
\hline \multicolumn{7}{|l|}{ Animal foods } \\
\hline \multicolumn{7}{|l|}{ GSTM1 } \\
\hline Null & 1.07 & $(0.56,2.08)$ & 0.843 & 1 & & \\
\hline Present & 1.25 & $(0.62,2.52)$ & 0.550 & 1.04 & $(0.82,1.32)$ & 0.760 \\
\hline \multicolumn{7}{|l|}{ GSTT1 } \\
\hline Null & 1.07 & $(0.55,2.07)$ & 0.861 & 1 & & \\
\hline Present & 1.18 & $(0.60,2.32)$ & 0.649 & 1.03 & $(0.81,1.30)$ & 0.836 \\
\hline \multicolumn{7}{|l|}{ GSTM1/GSTT1 } \\
\hline Double null & 1.18 & $(0.47,2.98)$ & 0.741 & 1 & & \\
\hline Either null & 0.95 & $(0.49,1.84)$ & 0.891 & 0.88 & $(0.64,1.21)$ & 0.423 \\
\hline $\begin{array}{c}\text { Double present } \\
\text { Sweets }\end{array}$ & 1.68 & $(0.60,4.68)$ & 0.329 & 1.17 & $(0.79 .1 .72)$ & 0.441 \\
\hline \multicolumn{7}{|l|}{ GSTM1 } \\
\hline Null & 0.68 & $(0.36,1.26)$ & 0.220 & 1 & & \\
\hline Present & 1.53 & $(0.73,3.20)$ & 0.266 & 1.23 & $(0.96,1.56)$ & 0.098 \\
\hline \multicolumn{7}{|l|}{ GSTT1 } \\
\hline Null & 0.85 & $(0.42,1.73)$ & 0.665 & & & \\
\hline Present & 1.02 & $(0.54,1.93)$ & 0.963 & 1.05 & $(0.82,1.33)$ & 0.712 \\
\hline \multicolumn{7}{|l|}{ GSTM1/GSTT1 } \\
\hline Double null & 0.59 & $(0.24,1.44)$ & 0.247 & 1 & & \\
\hline Either null & 1.04 & $(0.52,2.10)$ & 0.920 & 1.02 & $(0.74,1.41)$ & 0.897 \\
\hline Double present & 1.62 & $(0.61,4.33)$ & 0.343 & 1.27 & $(0.87,1.86)$ & 0.212 \\
\hline
\end{tabular}

* Model included the main and interaction effects of the GSTM1 and/or GSTT1 genotype (present vs. null) and dietary pattern (high $v s$. low) with adjustment for child's age, sex, total energy intake, multivitamin use and $\mathrm{BMI}$, and parental history of allergic diseases; ${ }^{\dagger} P$ for the stratified association between dietary patterns and $\mathrm{AD}$ by GST-null and present groups in the corresponding models; ${ }^{\ddagger} P$ for the multplicative association between $\mathrm{AD}$ and dietary pattern (high vs. low) in the GST present group compared to this association in the GST null group as reference (OR 1$)$ in the corresponding models. $N$ null; $p$ present. 


\section{Discussion}

Our findings suggest the association between the "traditional healthy" diet and reduced AD in children with the GSTM1-present genotype, and that children with GSTT1-present genotype may be more susceptible to this association. Such associations may not be relevant to an inactive GST allele such as the GST-null genotype.

Despite a lack of clear explanation, the absence of an association of the GSTM1- or GSTT1-null genotype with dietary components may suggest that certain polyphenols and carotenoids induce the expression of GST genes and increase the activities of GST enzymes [27-29]. Thus, the lack of an active GST allele would inhibit the response to dietary components that affect the expression of GST genes. Similar to our findings, a recent human intervention study [30] reported that a high-fruit juice and vegetable diet significantly increased erythrocyte GST activities and antioxidant capacity-related biomarker levels in blood from GSTM1- and GSTT1-present participants, whereas blood from GSTM1and GSTT1-null participants was unaffected. Even though the interactions of GST genotypes and diet in relation to AD have not been studied yet, previous reports [31,32] that examined these interactions in other diseases support our findings. Specifically, a significant inverse association between intake of carotenoid-rich or cruciferous vegetables and cancer risk was detected in carriers of the GSTM1or GSTT1-present genotype but not in those participants with the GSTM1- or GSTT1-null genotype. These results, as well as our findings, suggest that carriers of the GSTM1- or GSTT1-present genotype may be more responsive to dietary changes and could benefit more from healthy dietary patterns.

There have been conflicting reports on the association of GST present/null genotypes with $\operatorname{AD}[21,22,33]$. Consistent with our results, the GSTM1-present genotype has been reported to be relevant to AD only in the presence of specific environmental stimuli (prenatal smoke exposure) [34]. Detection of these gene-diet interactions suggests that it is important to determine the effects of gene polymorphisms as well as appropriate dietary information in order to account for the heterogeneity of previous findings. Further, unlike genetic determinants, diet can be modified by lifestyle intervention. Therefore, understanding the interactions between genetic and dietary factors is valuable in establishing dietary guidelines to reduce disease risk.

Several studies $[10,35-38]$ have shown the association between nutrient/food intakes and AD, but little is known regarding specific dietary patterns relevant to AD in relation to GST genes. Dietary pattern analysis considers the effects of the whole diet, including interactions and synergistic effects among nutrients and foods [39]. As nutrients and foods are not consumed in isolation, dietary patterns more accurately reflect eating habits than nutrient intake levels. The "traditional healthy" pattern that showed a positive impact on reduced $\mathrm{AD}$ in this study is somewhat similar to the "Mediterranean diet", which mainly involves higher intakes of micronutrients [40]. Adherence to a "Mediterranean diet" during pregnancy has been demonstrated as a protective factor against atopy until an age of 6.5 years (OR 0.55, 95\% CI 0.31-0.97) [41]. On the other hand, no association between the "Mediterranean diet" and AD has been reported in 6 to 7-year-old school children in Spain [42]. This discrepancy may be explained in part by a function of effect modifiers, like GST genes that we found in this study.

The limitations of this study are as follows. We assessed AD based on subjective measures without considering objective indices, although the ISAAC questionnaire used in this study is an internationally standardized protocol and has been widely used to determine the prevalence of allergic diseases in Korea [2,10,43]. Another limitation would be small sample size to identify a diet-gene interaction against $\mathrm{AD}$. We determined sample size at the beginning of this study based on antioxidant nutrients and $\mathrm{AD}$, but with little consideration of genetic characteristics. Possibly meaningful, but unmeasured or unexamined variables such as heavy metals [44] and other genes may also limit our findings $[45,46]$.

Regardless of these limitations, this study of gene-diet interaction in AD is meaningful because it is the first study to suggest the importance of genetic susceptibility that could play a crucial role in 
the "traditional healthy" diet on a child's AD. A large scale prospective study is needed to confirm these findings.

\section{Conclusions}

We conclude that healhty diet may reduce AD only in children with the GSTM1-present genotype. These findings suggest genetic susceptibility to the association between diet on AD.

Supplementary Materials: Supplementary materials can be accessed at: http:/ /www.mdpi.com/2072-6643/7/ $11 / 5473 /$ s1.

Acknowledgments: This study was supported in part by a grant from the Basic Research Program of the Korea Science and Engineering Foundation (R01-2006-00010887-0).

Author Contributions: S.-Y.O., J.C. designed research; S.-O.K. and H.A., conducted research; S.-Y.O, J.C., S.-O.K., and H.H. analyzed data, and S.-Y.O. and J.C. wrote the paper; S.H. reviewed the paper; S.-Y.O. had primary responsibility for final content.

Conflicts of Interest: The authors declare no conflict of interest.

\section{References}

1. Eichenfield, L.F.; Tom, W.L.; Berger, T.G.; Krol, A.; Paller, A.S.; Schwarzenberger, K.; Bergman, J.N.; Chamlin, S.L.; Cohen, D.E.; Cooper, K.D. Guidelines of care for the management of atopic dermatitis: Section 2. management and treatment of atopic dermatitis with topical therapies. J. Am. Acad. Dermatol. 2014, 71, 116-132. [PubMed]

2. Lee, J.Y.; Seo, J.H.; Kwon, J.W.; Yu, J.; Kim, B.J.; Lee, S.Y.; Kim, H.B.; Kim, W.K.; Kim, K.W.; Shin, Y.J.; et al. Exposure to gene-environment interactions before 1 year of age may favor the development of atopic dermatitis. Int. Arch. Allergy Immunol. 2012, 157, 363-371. [CrossRef] [PubMed]

3. Williams, H.C. Atopic dermatitis. N. Engl. J. Med. 2005, 352, 2314-2324. [CrossRef] [PubMed]

4. Bieber, T. Atopic dermatitis 2.0: From the clinical phenotype to the molecular taxonomy and stratified medicine. Allergy 2012, 67, 1475-1482. [CrossRef] [PubMed]

5. Larsen, F.S. Atopic dermatitis: A genetic-epidemiologic study in a population-based twin sample. J. Am. Acad. Dermatol. 1993, 28, 719-723. [CrossRef]

6. Omata, N.; Tsukahara, H.; Ito, S.; Ohshima, Y.; Yasutomi, M.; Yamada, A.; Jiang, M.; Hiraoka, M.; Nambu, M.; Deguchi, Y. Increased oxidative stress in childhood atopic dermatitis. Life Sci. 2001, 69, $223-228$. [CrossRef]

7. Tsukahara, H.; Shibata, R.; Ohshima, Y.; Todoroki, Y.; Sato, S.; Ohta, N.; Hiraoka, M.; Yoshida, A.; Nishima, S.; Mayumi, M. Oxidative stress and altered antioxidant defenses in children with acute exacerbation of atopic dermatitis. Life Sci. 2003, 72, 2509-2516. [CrossRef]

8. Kapp, A.; Zeck-Kapp, G.; Czech, W.; Schöpf, E. The chemokine rantes is more than a chemoattractant: characterization of its effect on human eosinophil oxidative metabolism and morphology in comparison with IL-5 and GM-CSF. J. Investig. Dermatol. 1994, 102, 906-914. [CrossRef] [PubMed]

9. Portugal, M.; Barak, V.; Ginsburg, I.; Kohen, R. Interplay among oxidants, antioxidants, and cytokines in skin disorders: Present status and future considerations. Biomed. Pharmacother. 2007, 61, 412-422. [CrossRef] [PubMed]

10. Oh, S.; Chung, J.; Kim, M.; Kwon, S.; Cho, B. Antioxidant nutrient intakes and corresponding biomarkers associated with the risk of atopic dermatitis in young children. Eur. J. Clin. Nutr. 2010, 64, $245-252$. [CrossRef] [PubMed]

11. Saadeh, D.; Salameh, P.; Baldi, I.; Raherison, C. Diet and allergic diseases among population aged 0 to 18 years: myth or reality? Nutrients 2013, 5, 3399-3423. [CrossRef] [PubMed]

12. Nurmatov, U.; Devereux, G.; Sheikh, A. Nutrients and foods for the primary prevention of asthma and allergy: Systematic review and meta-analysis. J. Allergy Clin. Immunol. 2011, 127, 724-733. [CrossRef] [PubMed]

13. Howard, A.L.; Robinson, M.; Smith, G.J.; Ambrosini, G.L.; Piek, J.P.; Oddy, W.H. ADHD is associated with a "western" dietary pattern in adolescents. J. Atten. Disord. 2011, 15, 403-411. [CrossRef] [PubMed] 
14. Millichap, J.G.; Yee, M.M. The diet factor in attention-deficit/hyperactivity disorder. Pediatrics 2012, 129, 330-337. [CrossRef] [PubMed]

15. Northstone, K.; Joinson, C.; Emmett, P.; Ness, A.; Paus, T. Are dietary patterns in childhood associated with IQ at 8 years of age? A population-based cohort study. J. Epidemiol. Community Health 2012, 66, 624-628. [CrossRef] [PubMed]

16. Smithers, L.G.; Golley, R.K.; Mittinty, M.N.; Brazionis, L.; Northstone, K.; Emmett, P.; Lynch, J.W. Dietary patterns at 6, 15 and 24 months of age are associated with IQ at 8 years of age. Eur. J. Epidemiol. 2012, 27, 525-535. [CrossRef] [PubMed]

17. Castaldi, P.J.; Cho, M.H.; Cohn, M.; Langerman, F.; Moran, S.; Tarragona, N.; Moukhachen, H.; Venugopal, R.; Hasimja, D.; Kao, E.; et al. The COPD genetic association compendium: A comprehensive online database of COPD genetic associations. Hum. Mol. Genet. 2010, 19, 526-534. [CrossRef] [PubMed]

18. Karban, A.; Krivoy, N.; Elkin, H.; Adler, L.; Chowers, Y.; Eliakim, R.; Efrati, E. Non-Jewish Israeli IBD patients have significantly higher glutathione S-transferase GSTT1-Null frequency. Dig. Dis. Sci. 2011, 56, 2081-2087. [CrossRef] [PubMed]

19. Thakur, H.; Gupta, L.; Sobti, R.C.; Janmeja, A.K.; Seth, A.; Singh, S.K. Association of GSTM1T1 GENES with COPD and prostate cancer in North Indian Population. Mol. Biol. Rep. 2011, 38, 1733-1739. [CrossRef] [PubMed]

20. Oniki, K.; Hori, M.; Saruwatari, J.; Morita, K.; Kajiwara, A.; Sakata, M.; Mihara, S.; Ogata, Y.; Nakagawa, K. Interactive effects of smoking and glutathione S-transferase polymorphisms on the development of non-alcoholic fatty liver Disease. Toxicol. Lett. 2013, 220, 143-149. [CrossRef] [PubMed]

21. Vavilin, V.; Safronova, O.; Lyapunova, A.; Lyakhovich, V.; Kaznacheeva, L.; Manankin, N.; Molokova, A. Interaction of GSTM1, GSTT1, and GSTP1 genotypes in determination of predisposition to atopic dermatitis. Bull. Exp. Biol. Med. 2003, 136, 388-391. [CrossRef] [PubMed]

22. Cho, H.; Uhm, Y.; Kim, H.; Ban, J.; Chung, J.; Yim, S.; Choi, B.; Lee, M. Glutathione S-transferase M1 (GSTM1) polymorphism is associated with atopic dermatitis susceptibility in a Korean population. Int. J. Immunogenet. 2011, 38, 145-150. [CrossRef] [PubMed]

23. Chung, J.; Oh, S.; Shin, Y. Association of glutathione-S-transferase polymorphisms with atopic dermatitis risk in preschool age children. Clin. Chem. Lab. Med. 2009, 47, 1475-1481. [CrossRef] [PubMed]

24. Shin, K.O.; Oh, S.; Park, H.S. Empirically derived major dietary patterns and their associations with overweight in Korean Preschool Children. Br. J. Nutr. 2007, 98, 416-421. [CrossRef] [PubMed]

25. World Health Organization. Physical Status: The Use of and Interpretation of Anthropometry; Report of a WHO Expert Committee; World Health Organization: Geneva, Switzerland, 1995.

26. Cody, R.; Smith, J. Applied Statistics and the SAS Programming Language, 5th ed.; Prentice-Hall: Upper Saddle River, NJ, USA, 2005.

27. Bhuvaneswari, V.; Velmurugan, B.; Nagini, S. Induction of glutathione-dependent hepatic biotransformation enzymes by lycopene in the hamster cheek pouch carcinogenesis model. J. Biochem. Mol. Biol. Biophys. 2002, 6, 257-260. [PubMed]

28. Munday, R.; Munday, J.S.; Munday, C.M. Comparative effects of mono-, di-, tri-, and tetrasulfides derived from plants of the Allium Family: Redox cycling in vitro and hemolytic activity and phase 2 enzyme induction in vivo. Free Radic. Biol. Med. 2003, 34, 1200-1211. [CrossRef]

29. Kuo, W.; Chou, F.; Young, S.; Chang, Y.; Wang, C. Geniposide activates GSH S-transferase by the induction of GST M1 and GST M2 Subunits involving the transcription and phosphorylation of MEK-1 Signaling in rat hepatocytes. Toxicol. Appl. Pharmacol. 2005, 208, 155-162. [CrossRef] [PubMed]

30. Yuan, L.; Zhang, L.; Ma, W.; Zhou, X.; Ji, J.; Li, N.; Xiao, R. Glutathione S-transferase M1 and T1 gene polymorphisms with consumption of high fruit-juice and vegetable diet affect antioxidant capacity in healthy adults. Nutrition 2013, 29, 965-971. [CrossRef] [PubMed]

31. Joseph, M.A.; Moysich, K.B.; Freudenheim, J.L.; Shields, P.G.; Bowman, E.D.; Zhang, Y.; Marshall, J.R.; Ambrosone, C.B. Cruciferous vegetables, genetic polymorphisms in glutathione S-transferases M1 and T1, and prostate cancer risk. Nutr. Cancer 2004, 50, 206-213. [CrossRef] [PubMed]

32. Wang, L.I.; Giovannucci, E.L.; Hunter, D.; Neuberg, D.; Su, L.; Christiani, D.C. Dietary intake of cruciferous vegetables, glutathione S-transferase (GST) polymorphisms and lung cancer risk in a Caucasian population. Cancer Causes Control 2004, 15, 977-985. [CrossRef] [PubMed] 
33. Safronova, O.; Vavilin, V.; Lyapunova, A.; Makarova, S.; Lyakhovich, V.; Kaznacheeva, L.; Manankin, N.; Batychko, O.; Gavalov, S. Relationship between glutathione S-transferase P1 polymorphism and bronchial asthma and atopic dermatitis. Bull. Exp. Biol. Med. 2003, 136, 73-75. [CrossRef] [PubMed]

34. Wang, I.; Guo, Y.L.; Lin, T.; Chen, P.; Wu, Y. GSTM1, GSTP1, prenatal smoke exposure, and atopic dermatitis. Ann. Allergy Asthma Immunol. 2010, 105, 124-129. [CrossRef] [PubMed]

35. Miyake, Y.; Sasaki, S.; Tanaka, K.; Hirota, Y. Consumption of vegetables, fruit, and antioxidants during pregnancy and wheeze and eczema in infants. Allergy 2010, 65, 758-765. [CrossRef] [PubMed]

36. Okuda, M.; Bando, N.; Terao, J.; Sasaki, S.; Sugiyama, S.; Kunitsugu, I.; Hobara, T. Association of serum carotenoids and tocopherols with atopic diseases in japanese children and adolescents. Pediatr. Allergy Immunol. 2010, 21, e705-e710. [CrossRef] [PubMed]

37. Nwaru, B.I.; Erkkola, M.; Lumia, M.; Kronberg-Kippilä, C.; Ahonen, S.; Kaila, M.; Ilonen, J.; Simell, O.; Knip, M.; Veijola, R. Maternal intake of fatty acids during pregnancy and allergies in the offspring. Br. J. Nutr. 2012, 108, 720-732. [CrossRef] [PubMed]

38. Rosenlund, H.; Magnusson, J.; Kull, I.; Håkansson, N.; Wolk, A.; Pershagen, G.; Wickman, M.; Bergström, A. Antioxidant intake and allergic disease in children. Clin. Exp. Allergy 2012, 42, 1491-1500. [CrossRef] [PubMed]

39. Fung, T.T.; Hu, F.B.; Holmes, M.D.; Rosner, B.A.; Hunter, D.J.; Colditz, G.A.; Willett, W.C. Dietary patterns and the risk of postmenopausal breast cancer. Int. J. Cancer 2005, 116, 116-121. [CrossRef] [PubMed]

40. Chatzi, L.; Kogevinas, M. Prenatal and childhood mediterranean diet and the development of asthma and allergies in children. Public Health Nutr. 2009, 12, 1629-1634. [CrossRef] [PubMed]

41. Chatzi, L.; Torrent, M.; Romieu, I.; Garcia-Esteban, R.; Ferrer, C.; Vioque, J.; Kogevinas, M.; Sunyer, J. Mediterranean diet in pregnancy is protective for wheeze and atopy in childhood. Thorax 2008, 63, 507-513. [CrossRef] [PubMed]

42. Suarez-Varela, M.M.; Alvarez, L.G.; Kogan, M.D.; Ferreira, J.C.; Martinez Gimeno, A.; Aguinaga Ontoso, I.; Gonzalez Diaz, C.; Arnedo Pena, A.; Dominguez Aurrecoechea, B.; Busquets Monge, R.M.; et al. Diet and prevalence of atopic eczema in 6 to 7-year-old schoolchildren in Spain: ISAAC Phase III. J. Investig. Allergol. Clin. Immunol. 2010, 20, 469-475. [PubMed]

43. Lee, S. Prevalence of childhood asthma in Korea: International study of asthma and allergies in childhood. Allergy Asthma Immunol. Res. 2010, 2, 61-64. [CrossRef] [PubMed]

44. Kim, J.H.; Jeong, K.S.; Ha, E.; Park, H.; Ha, M.; Hong, Y.; Lee, S.; Lee, K.Y.; Jeong, J.; Kim, Y. Association between prenatal exposure to cadmium and atopic dermatitis in infancy. J. Korean Med. Sci. 2013, 28, 516-521. [CrossRef] [PubMed]

45. Alvarez, A.E.; de Lima Marson, F.A.; Bertuzzo, C.S.; Arns, C.W.; Ribeiro, J.D. Epidemiological and genetic characteristics associated with the severity of acute viral bronchiolitis by respiratory syncytial virus. J. Pediatr. 2013, 89, 531-543. [CrossRef] [PubMed]

46. Jung, Y.; Seo, J.; Kim, H.Y.; Kwon, J.; Kim, B.; Kim, H.; Lee, S.; Jang, G.C.; Song, D.J.; Kim, W.K. The relationship between asthma and bronchiolitis is modified by TLR4, CD14, and IL-13 polymorphisms. Pediatr. Pulmonol. 2015, 50, 8-16. [CrossRef] [PubMed]

(C) 2015 by the authors; licensee MDPI, Basel, Switzerland. This article is an open access article distributed under the terms and conditions of the Creative Commons by Attribution (CC-BY) license (http://creativecommons.org/licenses/by/4.0/). 